Recepción: 20 / 04 / 2017

Aceptación: 20 / 05 / 2017

Publicación: 15 / 06 / 2017
Ciencias de la Comunicación

Artículo de Investigación

\title{
El tratamiento de la investigación periodística en el programa en carne propia
}

Journalistic investigation procedure in the carne

propia program

Procedimento de investigação jornalística no programa

carne propia

Johana M. Balseca-Mera ${ }^{\mathrm{I}}$ johana.balseca@hotmail.com

Lorena C. Álvarez-Garzón II lorena.alvarez@hotmail.com

Alex H. Mullo-López ${ }^{\text {III }}$ alex.mullo@utc.edu.ec

Correspondencia: alex.mullo@utc.edu.ec

I. Licenciada en Comunicación Social; Universidad Técnica de Cotopaxi; Cotopaxi, Ecuador.

II. Magister en Educación y Desarrollo Social, Licenciada en Ciencias de la Educación Especialización Educación de Adultos, Licenciada en Comunicación Social; Universidad Técnica de Cotopaxi; Cotopaxi, Ecuador.

III. Diploma Superior en Planificación Estratégica de la Comunicación, Magister en Comunicación Periodística, Institucional y Empresarial, Especialista en Comunicación e Imagen Corporativa, Licenciado en Comunicación Social; Universidad Técnica de Cotopaxi; Cotopaxi, Ecuador. 


\section{Resumen}

La presente investigación procura analizar cómo se aborda el periodismo de investigación en el programa "En Carne Propia" que emite Canal UNO de lunes a viernes en horario nocturno de 21:30 a 22:30. Se tomó como referencia los criterios de los autores: Giovanni Sartori, Heriberto Cardoso, Gerald Imbert, Silvio Rodríguez, respecto al ejercicio del periodismo de investigación y de libros como Zoo Visual, Homo Sapiens, Investigación Periodística, Formatos Televisivos, La intimidad como Espectáculo; entre otros autores y temas que aportaron al sustento teórico y que coinciden en que la televisión y su programación deben direccionarse a informar, educar y entretener.

La metodología aplicada fue cualitativa es decir, se realizaron grupos focales, análisis de contenidos y entrevistas especializadas en torno al programa en estudio, se encontró que los contenidos y el proceso de producción hasta presentación al aire presentan serias deficiencias y no responde a los principales objetivos de la comunicación, sin embargo es un programa de porcentajes altos de rating en nuestro país, la sociedad lo acepta y lo sigue pese a que desde el punto de vista psicológico causa efectos como la naturalización de la violencia en quienes observan en este tipo de programas televisivos.

La investigación, propone realizar talleres de análisis de contenidos enfocados a fomentar el "uso crítico de la televisión como medio de comunicación social", para visibilizar la existencia de los defensores de audiencias y lectores: sus funciones, los objetivos y los beneficios que éstos tienen para los televidentes y la importancia de una postura crítica ante los medios.

Palabras clave: En Carne Propia; investigación periodística; psicología, rating; defensores de audiencias y lectores; uso crítico de la televisión; naturalización de la violencia; tratamiento ético de la información. 


\section{Abstract}

This research examines how investigative journalism is addressed in the "En Carne Propia" that emits Channel One from Monday to Saturday 21:30 to 22:30 the creiteria id the authors: Giovanni Sartori, Heriberto Cardoso, Geral Imbert, Silvio Rodríguez, regarding the exercise of investigative journalism and books like Visual Zoo, Homo-Sapiens, investigative Journalims, Television Formats, Intimacy as Show: among other authors and themes that contributed to the theoretical and agree that televiion and its programming must be routed to inform, educate and entertain.

The methodology was qualitative with focus groups, content analysis and specialized interviews around the program under study, it was found that the contents and the process of production to present in the air show serious deficiencies and does nor address the main objectives were conducted communication, however, it is a program of high percentages of harmony in our country, society accepts and follows although from the standpoint of psychological cause effects such as naturalization of violence on those who watch this type of program televisión.

The researching proposes workshops focuses analysus at promoting "critical use of televisión as a means of social communicarion" to make visible the existence of the defenders of audiences and readers content; its functions, objectives and the benefits they have for viewers and the importance of a critical approach to the media

Key words: En Carne Propia; journalistic resear, psychology; rating; defenders audiences and readers; critical use of televisión; naturalization of violence; technical treatment of information. 


\section{Resumo}

A presente investigação procura analizar como se abordar o período de pesquisa no programa "En Carne Propia" que emite Canal UNO de lunes a sexta-feira em horário nocturno de 21:30 às 22:30. Tomás como referência dos critérios dos autores: Giovanni Sartori, Heriberto Cardoso, Gerald Imbert, Silvio Rodríguez, respeito ao exercício do periodismo de pesquisa e de livros como Zoo Visual, Homo Sapiens, Investigação Periodística, Formatos Televisivos, La intimidad como Espectáculo; Entre outros autores e temas que aportaram ao sustento teórico e que coincidem em que a televisão e a programação são fornecidas a informa, educar y entretener.

A metodologia aplicada foi qualitativa e diretiva, realizou-se grupos focales, análise de conteúdos e entrevistas especializadas em torno do programa em estudo, encontrou-se o conteúdo e o processo de produção até a apresentação ao ar apresenta serias deficiências e não responda a os principais objetivos De la comunicación, sin embargo, é um programa de porcentagens altas de rating em nosso país, a sociedade e aquilo que está em conformidade com o tema do ponto de vista psicológico causa efeitos como a naturalização da violência em quem observa este tipo de programas Televisivos.

A pesquisa, propone a realização de instrumentos de análise de conteúdos enfocados e fomentar o "uso crítico da televisão como meio de comunicação social", para visibilizar a existência de defensores de audiências e lectores: sus funciones, os objetivos e os benefícios que possuem. Para os televidentes e a importância de uma crítica crítica dos meios.

Palavras chave: En Carne Propia; Investigación periodística; Psicologia, classificação; Defensores de audiências e lectores; Uso crítico da televisão; Naturalización de violência; Tratamento ético de informação 


\section{Introducción.}

Se sabe que la investigación es considerada una actividad humana, orientada a la obtención de nuevos conocimientos y su aplicación para la solución a problemas o interrogantes de carácter científico, cultural, social; en este aspecto Silvio Rodríguez, sostiene que:

El periodista investigador, será el que, utilizando técnicas habituales de la profesión $\mathrm{u}$ otras específicas y/o habitualmente atribuibles a profesiones ajenas a la suya (detective, policía, abogado, historiador, etc.) elabora una información producto de un número indeterminado de fuentes (atribuibles o no) y de un análisis personal de datos, contrastados con mayor o menor eficacia, que le conducen a comunicar una noticia sobre una realidad, que por su configuración y naturaleza, estaba destinada a permanecer oculta durante un período de tiempo indefinido (...), dando a conocer una información que "sin su explícita intervención, nunca o muy difícilmente hubiese podido aflorar.

(Rodriguez, 2000,p.228 )

Es necesario, dentro del ejercicio profesional de un comunicador social o periodista, saber hasta qué punto se puede prestar la imagen, conocimientos y credibilidad para hacer un programa televisivo que muestra la realidad social o en el caso del programa En Carne Propia, trabajar para cumplir con lo que dice su presentador:

En carne propia es un programa investigativo donde enfoca hechos reales, de personas que han vivido experiencias propias, dirigido por un periodista que nos permite conocer con profundidad la realidad de los hechos que se suscitan a diario en la Ciudad, donde el principal reto es de llegar a la verdad donde quiera que ésta se encuentre. (José Delgado, entrevista personal, N³, Mayo 2013) 
Cuando el trabajo periodístico del programa En Carne Propia se presenta como un equipo capaz de llegar a la verdad en donde quiera que se encuentre, es el punto del que inicia la indagación porque al no contar con escenarios fijos sino improvisados y que muchos de ellos incluso invaden la intimidad de una persona o de una sociedad, es prematuro e inoportuno afirmar o negar si se realiza una investigación.

La presente investigación busca analizar de qué manera se aborda el periodismo investigativo en el programa "En Carne Propia" e posteriormente identificar cuál es la relación que existe entre la idea de periodismo investigativo que ofrece este programa, y el concepto de investigación que se enmarca en la Comunicación Social. Desde otro punto de vista se pretende saber si esta producción tiene presente la ética de los que hacen posible la emisión de este programa. Esto basado en los códigos deontológicos; severamente ligado a la humanidad del periodista y del conocimiento que tenemos de no desprestigiar a la gente y mucho menos naturalizar la violencia.

\section{Materiales y métodos.}

\section{Tipo de investigación}

El trabajo se enmarca en ser una investigación cualitativa de campo e investigación bibliográfica. A más de ser un tema poco tratado, el objetivo es analizar el impacto psicológico y social que provocan los contenidos de un programa investigativo y el tratamiento de la investigación periodística del programa En Carne Propia en las personas.

\section{Unidad de estudio}


Para el presente análisis se tomó como muestra ocho personas que conformarán un grupo focal, entre su mayoría estudiantes de comunicación social y docentes de la Universidad Técnica de Cotopaxi; con quienes se trabajará el temario propuesto.

\section{Técnicas metodológicas}

Para la recolección de datos se usaron tres técnicas que detalla a continuación:

Ficha de análisis y temario

Grupo focal

Entrevista a profundidad 

Análisis de datos

Ficha de análisis

Para la investigación, se desarrolló estas fichas logrando analizar el fondo y la forma del programa "En Carne Propia”. Para lo cual realizó la observación y seguimiento de la producción durante una semana comprendida entre los días: 01-02-03-04 y 05 de febrero del 2016; en los que el programa se transmite por la señal de canal UNO en horario de 20:30 a 22:30. La tesista considera importante recalcar que los textos que se detallan en la columna "contenido" son diálogos y frases textuales de los actores en las respectivas notas.

\begin{tabular}{|c|c|c|c|c|c|}
\hline FECHA & TÍTULO & ACTORES & $\begin{array}{c}\text { CONTENID } \\
0\end{array}$ & $\begin{array}{c}\text { SEGUIMIENT } \\
0\end{array}$ & OBSERVACIÓN \\
\hline $\begin{array}{l}\text { LUNES } \\
\text { 01 DE } \\
\text { FEBRER } \\
\text { O } 2016\end{array}$ & $\begin{array}{l}\text { MACHETEADO } \\
\text { S POR } \\
\text { CELOSOS }\end{array}$ & $\begin{array}{l}\text { SONIA } \\
\text { MACHETERO } 1 \\
\text { MACHETERO } 2 \\
\text { TESTIMONIO } \\
\text { HOMBRE }\end{array}$ & $\begin{array}{l}\text { (En los } \\
\text { exteriores de } \\
\text { la casa de } \\
\text { Sonia). Son } \\
\text { dos hombres } \\
\text { que quisieron } \\
\text { demostrar su } \\
\text { hombría y } \\
\text { pelearon entre } \\
\text { ellos por mí. } \\
\text { Persigue al } \\
\text { conviviente } \\
\text { de la ex } \\
\text { cuñada. } \\
\text { Se separó de } \\
\text { su esposa en } \\
\text { diciembre. } \\
\text { Nosotros no } \\
\text { podíamos } \\
\text { hacer nada, } \\
\text { los } \\
\text { escándalos } \\
\text { son comunes, } \\
\text { siempre } \\
\text { hacen farra } \\
\text { ahí. }\end{array}$ & & $\begin{array}{l}\text { Inicia el programa con } \\
\text { un breve saludo del } \\
\text { presentador y } \\
\text { clasificación de } \\
\text { contenidos tipo "B". En } \\
\text { un recuadro } \\
\text { "ENTRETENIMIENT } \\
\text { O". } \\
\text { (APTO PARA TODO } \\
\text { PÚBLICO, CON } \\
\text { VIGILANCIA DE } \\
\text { UNA PERSONA } \\
\text { ADULTA. SE PUEDE } \\
\text { TRANSMITIR EN } \\
\text { CUALQUIER } \\
\text { HORARIO } \\
\text { ESPECIALMENTE EN } \\
\text { EL DE } \\
\text { "RESPONSABILIDAD } \\
\text { COMPARTIDA" DE } \\
\text { 18:00 A 22:00 PERO } \\
\text { NO EN HORARIO } \\
\text { FAMILIAR). Según el } \\
\text { artículo 65 de la Ley } \\
\text { Orgánica de } \\
\text { Comunicación. }\end{array}$ \\
\hline & $\begin{array}{l}\text { ENCONTRADO } \\
\text { EN EL } \\
\text { SALADO }\end{array}$ & $\begin{array}{l}\text { TESTIMONIO } \\
\text { HOMBRE } \\
\text { REPRESENTANT }\end{array}$ & $\begin{array}{l}\text { (Al borde del } \\
\text { salado) } \\
\text { Describe que } \\
\text { el cadáver } \\
\text { estaba: } \\
\text { amarrado, }\end{array}$ & & \\
\hline
\end{tabular}


El tratamiento de la investigación periodística en el programa en carne propia

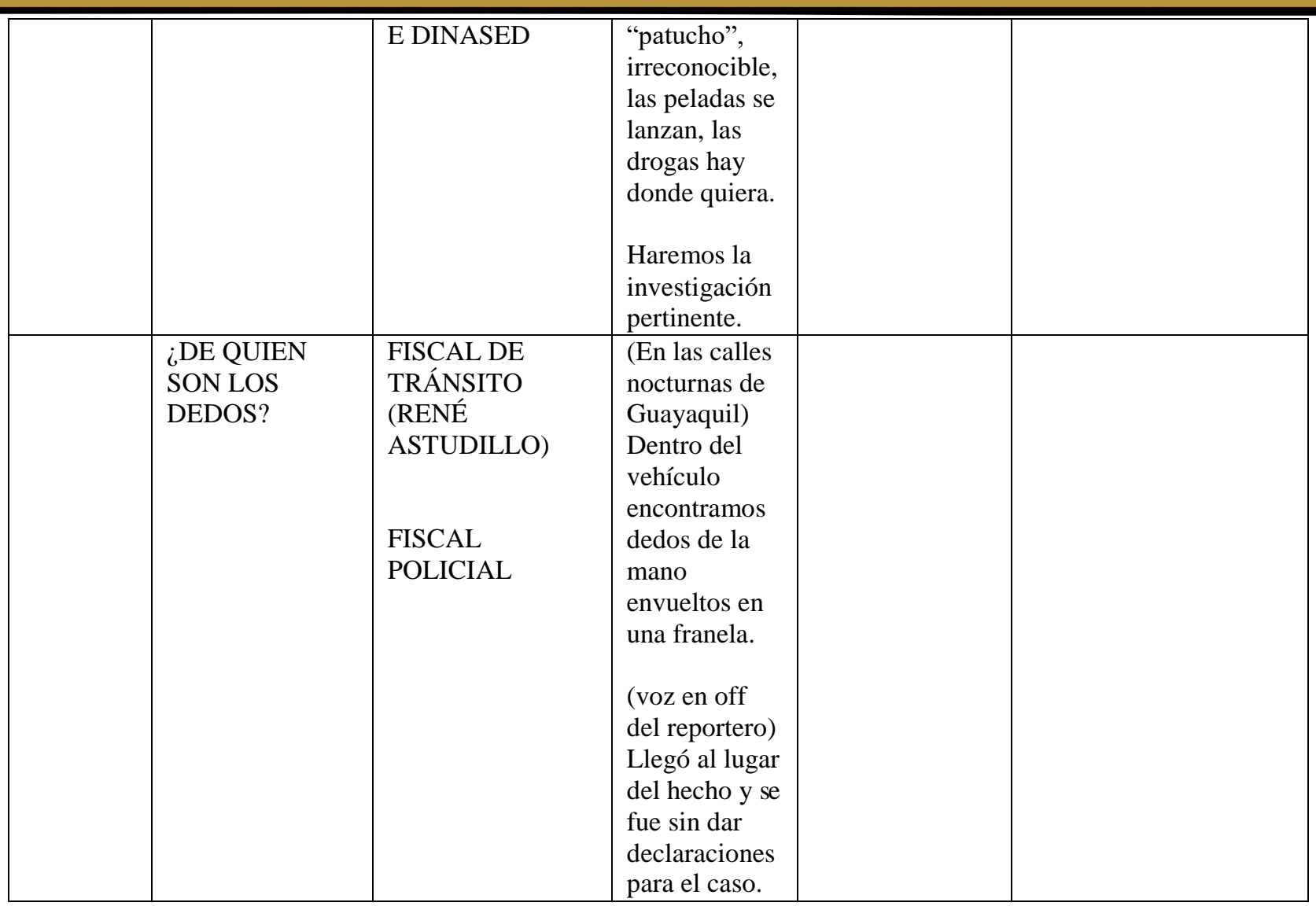

\begin{tabular}{|c|c|c|}
\hline $\begin{array}{ll}\text { LOBOS } & \\
\text { VESTIDOS } & \text { DE } \\
\text { OBEJAS } & \end{array}$ & $\begin{array}{l}\text { MORADORES } \\
\text { DEL CERRO LAS } \\
\text { CABRAS }\end{array}$ & $\begin{array}{l}\text { (En una reunión del barrio, } \\
\text { frente a autoridades y } \\
\text { pobladores) } \\
\text { Aquí se realizan bailo } \\
\text { terapias. } \\
\text { Hace tres años vivíamos } \\
\text { amenazados. } \\
\text { Estamos agradecidos, pero } \\
\text { pedimos que se vayan los } \\
\text { delincuentes del barrio } \\
\text { porque, aunque ha } \\
\text { disminuido los robos los } \\
\text { delincuentes están aquí } \\
\text { mismo frente a nosotros } \\
\text { riéndose, yo les digo en su } \\
\text { cara "NO LES TENGO } \\
\text { MIEDO". Los vecinos no } \\
\text { dicen nada, pero yo no les } \\
\text { tengo miedo. } \\
\text { No daremos más espacio a } \\
\text { los micro traficantes del } \\
\text { sector. } \\
\text { Dentro de poco esto será un } \\
\text { lugar turístico. El trabajo se } \\
\text { desplaza y ahí debemos }\end{array}$ \\
\hline
\end{tabular}


Johana M. Balseca-Mera; Lorena C. Álvarez-Garzón; Alex H. Mullo-López

\begin{tabular}{|c|c|c|c|c|}
\hline & & $\begin{array}{lcc}\text { decir } & \text { NO } & \text { MÁS } \\
\text { MICROTRÁFICO. } & \end{array}$ & & \\
\hline $\begin{array}{l}\text { BALEADO EN } \\
\text { BAR } \\
\text { CLANDESTINO }\end{array}$ & $\begin{array}{l}\text { TESTIMONIO } \\
\text { HOMBRE } \\
\text { DUEÑA DEL BAR } \\
\text { HIJO DE LA } \\
\text { DUEÑA DEL BAR }\end{array}$ & $\begin{array}{l}\text { (Calles de Guayaquil) } \\
\text { Hubo un problema en el bar } \\
\text { a las tres de la mañana. } \\
\text { Nosotros no huimos porque } \\
\text { no tenemos nada que } \\
\text { ocultar. } \\
\text { Hay control de la policía, } \\
\text { pero vienen y se van } \\
\text { enseguida. La misma gente } \\
\text { del barrio viene al bar y no } \\
\text { sé porque ahora hablan mal } \\
\text { de mí. } \\
\text { "si yo no tuviera palancas } \\
\text { ahora estuviera preso por lo } \\
\text { que pasó". }\end{array}$ & $\begin{array}{l}\text { Hace un } \\
\text { año hubo } \\
\text { otro joven } \\
\text { baleado en } \\
\text { este mismo } \\
\text { bar. (voz en } \\
\text { off del } \\
\text { reportero) }\end{array}$ & \\
\hline $\begin{array}{l}\text { GASOLINERA } \\
\text { ASALTADA } \\
\text { CUATRO VECES }\end{array}$ & $\begin{array}{l}\text { CONDUCTORES } \\
\text { POLICÍA } \\
\text { DESPACHADORA }\end{array}$ & $\begin{array}{l}\text { (En la gasolinera) } \\
\text { Ellos andan más armados } \\
\text { que la misma policía. La } \\
\text { policía debe tomar cartas en } \\
\text { el asunto, uno nace, pero no } \\
\text { sabe dónde irá a morir. } \\
\text { Recibimos la llamada del } \\
911 . \\
\text { Agredida por ladrones } \\
\text { (imágenes). } \\
\text { Tenemos la precaución de } \\
\text { depositar poco a poco el } \\
\text { dinero y si nos roban ya nos } \\
\text { roban poco. }\end{array}$ & $\begin{array}{l}\text { En menos } \\
\text { de dos } \\
\text { meses es la } \\
\text { cuarta vez } \\
\text { que le } \\
\text { asaltan. } \\
\text { (voz en off } \\
\text { del } \\
\text { reportero) }\end{array}$ & \\
\hline $\begin{array}{l}\text { DECOMISARON } \\
200 \text { KILOS DE } \\
\text { DROGA }\end{array}$ & $\begin{array}{l}\text { TENIENTE } \\
\text { FRANKLIN } \\
\text { GALLEGOS } \\
\\
\text { POLICÍA } \\
\text { MINISTRO DEL } \\
\text { INTERIOR } \\
\end{array}$ & $\begin{array}{l}\text { (en los interiores de una } \\
\text { casa) } \\
\text { Los padres deben educar y } \\
\text { cuidar a sus hijos en casa. Al } \\
\text { pez gordo es difícil de } \\
\text { cogerlo. } \\
\text { Muestran la cantidad y el } \\
\text { lugar en donde se halló la } \\
\text { droga. } \\
\text { Confirmó la desarticulación } \\
\text { de la banda que expendía } \\
\text { droga liderada por cabos de } \\
\text { la policía en servicio activo. } \\
\text { El gobierno debe } \\
\text { incrementar cursos en los }\end{array}$ & & \\
\hline
\end{tabular}


El tratamiento de la investigación periodística en el programa en carne propia

\begin{tabular}{|c|c|c|c|}
\hline & & $\begin{array}{l}\text { que se entretengan los } \\
\text { jóvenes. }\end{array}$ & \\
\hline & $\begin{array}{l}\text { PRIMERA PAUSA } \\
\text { COMERCIAL }\end{array}$ & $\begin{array}{l}\text { LA GANGA. } \\
\text { TALLER DE TV E } \\
\text { INVESTIGACION } \\
\text { PERIODISTICA DICTADO } \\
\text { POR JOSE DELGADO. } \\
\text { NOVELA LA HIJA DEL } \\
\text { MARIACHI (AVANCE). } \\
\text { NOTICIERO LOS } \\
\text { CONFIABLES } \\
\text { (HORARIO). } \\
\text { ACEITE DE COCINA LA } \\
\text { FAVORITA. } \\
\text { DIRECTV HD. } \\
\text { NOVELA HASTA QUE LA } \\
\text { PLATA NOS SEPARE } \\
\text { (AVANCE). }\end{array}$ & \\
\hline \multirow[t]{2}{*}{$\begin{array}{l}\text { ABUELITO } \\
\text { AGREDIDO } \\
\text { LE DIO PARO } \\
\text { MIENTRAS } \\
\text { ASALTABA }\end{array}$} & & $\begin{array}{ll}\text { SEGMENTO: } & \\
\text { "VIDEOS } & \text { QUE } \\
\text { CONMOSIONAN } & \text { AL } \\
\text { MUNDO" } & \end{array}$ & 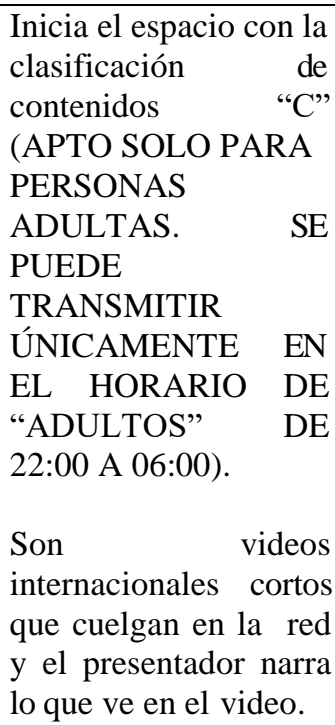 \\
\hline & $\begin{array}{l}\text { SEGUNDA PAUSA } \\
\text { COMERCIAL }\end{array}$ & $\begin{array}{l}\text { NOVELA LA HIJA DEL } \\
\text { MARIACHI (AVANCE). } \\
\text { BAILA LA NOCHE (BLN } \\
\text { LA COMETENCIA). } \\
\text { BECAS PARA JOVENES } \\
\text { EJEMPLARES DE LA } \\
\text { ALCALDÍA } \\
\text { GUAYAQUIL. } \\
\text { NOVELA HASTA QUE LA } \\
\text { PLATA NOS SEPARE } \\
\text { (AVANCE). }\end{array}$ & \\
\hline $\begin{array}{l}\text { ROBO A } \\
\text { TRANSEUNTE }\end{array}$ & $\begin{array}{l}\text { TESTIMONIO } \\
\text { HOMBRE } \\
\text { GUARDIA DE LA }\end{array}$ & $\begin{array}{l}\text { Al que pasa se le llevan el } \\
\text { celular y si no se deja robar } \\
\text { lo van matando. } \\
\text { Evitó un asalto, facilita }\end{array}$ & \\
\hline
\end{tabular}


Johana M. Balseca-Mera; Lorena C. Álvarez-Garzón; Alex H. Mullo-López

\begin{tabular}{|c|c|c|c|}
\hline & ZONA & tomas del ECU 911. & \\
\hline & $\begin{array}{l}\text { TERCERA PAUSA } \\
\text { COMERCIAL }\end{array}$ & $\begin{array}{l}\text { NOVELA HASTA QUE LA } \\
\text { PLATA NOS SEPARE } \\
\text { (AVANCE). } \\
\text { NOVELA LA HIJA DEL } \\
\text { MARIACHI (AVANCE). } \\
\text { LA GANGA. } \\
\text { AMIGOS INTIMOS } \\
\text { (HORARIO). } \\
\text { FARANDULEROS } \\
\text { (HORARIO). } \\
\text { NOVELA LA HIJA DEL } \\
\text { MARIACHI (AVANCE). }\end{array}$ & \\
\hline \multirow[t]{2}{*}{$\begin{array}{l}\text { A MERCED DE } \\
\text { LA CORRIENTE } \\
\text { CONDUCTOR } \\
\text { DESPISTADO }\end{array}$} & & $\begin{array}{l}\text { SEGMENTO: } \\
\text { "VIDEOS } \\
\text { CONMOSIONAN } \\
\text { MUNDO" }\end{array}$ & 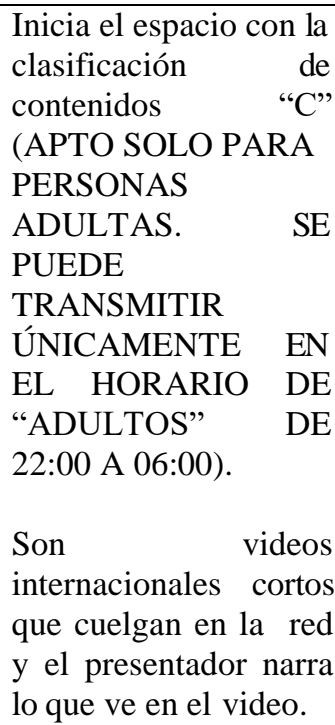 \\
\hline & $\begin{array}{l}\text { CUARTA PAUSA } \\
\text { COMERCIAL }\end{array}$ & $\begin{array}{l}\text { LA GANGA. } \\
\text { TALLER DE TV E } \\
\text { INVESTIGACIÓN } \\
\text { PERIODÍSTICA DICTADO } \\
\text { POR JOSÉ DELGADO. } \\
\text { NOVELA HASTA QUE LA } \\
\text { PLATA NOS SEPARE } \\
\text { (AVENCE). } \\
\text { BLN LA COMPETENCIA. } \\
\text { TV CABLE SATELITAL. } \\
\text { HOTEL SOL DE } \\
\text { ORIENTE. } \\
\text { NOVELA PEDRO EL } \\
\text { ESCAMOSO (AVANCE). } \\
\text { NOVELA LA HIJA DEL } \\
\text { MARIACHI (AVANCE). }\end{array}$ & \\
\hline $\begin{array}{l}\text { NO LOS DEJAN } \\
\text { DORMIR }\end{array}$ & $\begin{array}{l}\text { LA } \quad \text { SENORA } \\
\text { DENUNCIANTE }\end{array}$ & $\begin{array}{l}\text { Los llamé porque desde que } \\
\text { llegué del exterior, este antro } \\
\text { frente a mi casa no me deja } \\
\text { dormir. } \\
\text { El alcohol y la droga, las } \\
\text { chicas se prostituyen, son } \\
\text { chicos pobres, vienen } \\
\text { lesbianas, maricones, etc... }\end{array}$ & $\begin{array}{l}\text { Inicia el espacio con la } \\
\text { clasificación de } \\
\text { contenidos "C" } \\
\text { (APTO SOLO PARA } \\
\text { PERSONAS } \\
\text { ADULTAS. } \\
\text { PUEDE } \\
\text { TRANSMITIR }\end{array}$ \\
\hline
\end{tabular}


El tratamiento de la investigación periodística en el programa en carne propia

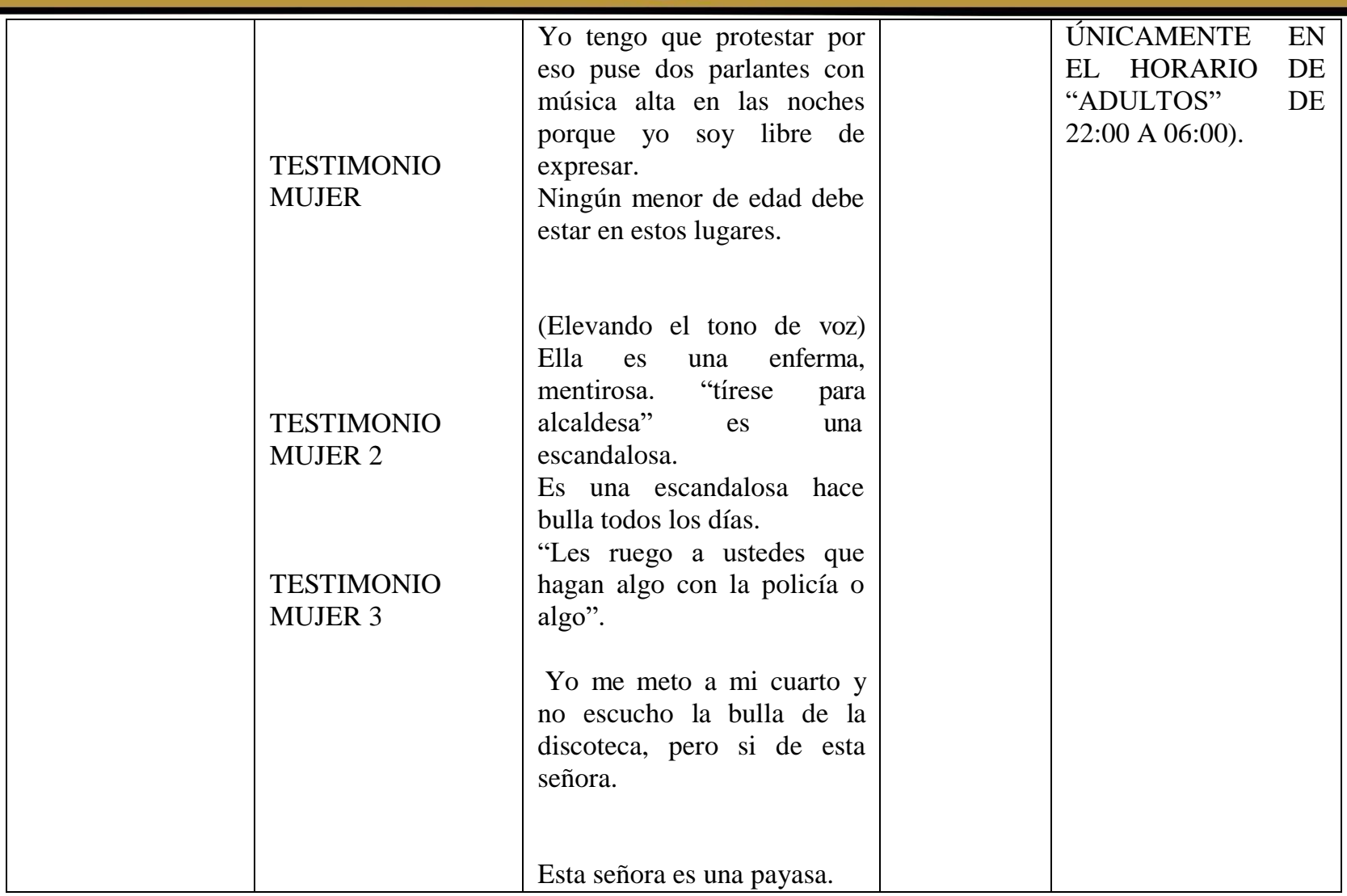

Este análisis se realizó de la misma forma para los días martes 02 de febrero del 2016, miércoles 03 de febrero del 2016, jueves 04 de febrero del 2016 y viernes 05 de febrero del 2016.

\section{Grupo focal}

A continuación, se presenta una encuesta desarrollada a la Licenciada Magaly Benalcázar en donde se desea rescatar información relevante acerca del estilo periodístico del programa "En carne propia"

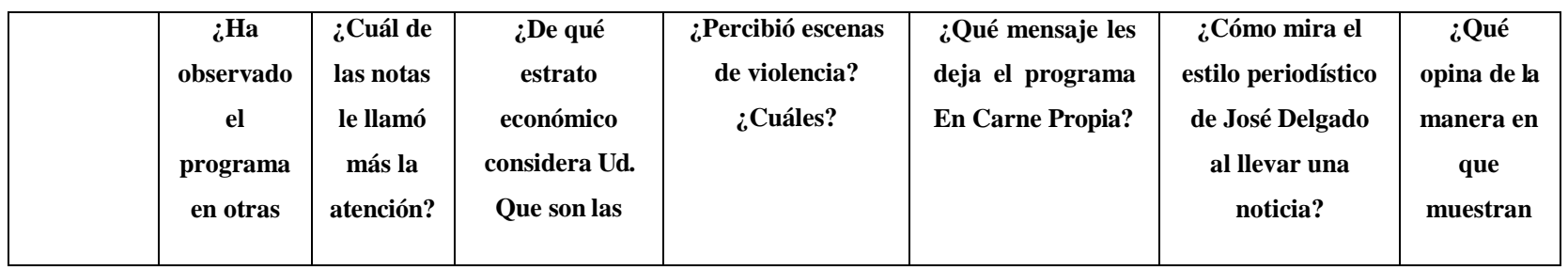


Johana M. Balseca-Mera; Lorena C. Álvarez-Garzón; Alex H. Mullo-López

\begin{tabular}{|c|c|c|c|c|c|c|}
\hline & ocasiones? & $\begin{array}{l}\text { personas que } \\
\text { aparecieron en } \\
\text { el video? }\end{array}$ & & & $\begin{array}{l}\text { ¿Qué percepción } \\
\text { les deja de la } \\
\text { comunicación? }\end{array}$ & $\begin{array}{c}\text { ciertas } \\
\text { imágenes y } \\
\text { noticias el } \\
\text { programa? }\end{array}$ \\
\hline $\begin{array}{l}\text { Lic. } \\
\text { Magaly } \\
\text { Benalcázar }\end{array}$ & $\begin{array}{l}\text { Sí, en } \\
\text { ocasiones. }\end{array}$ & 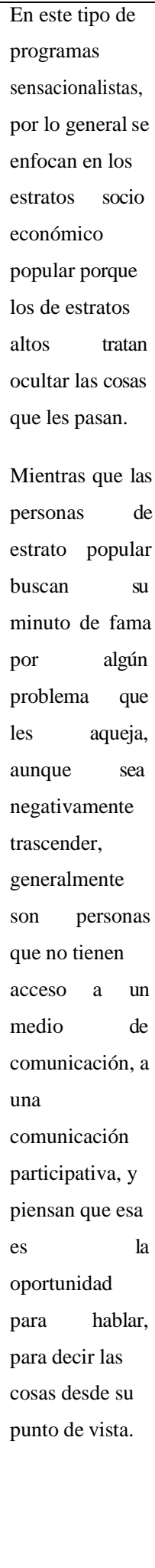 & $\begin{array}{l}\text { El programa tiene } \\
\text { un alto contenido } \\
\text { de violencia } \\
\text { simbólica. El decir } \\
\text { que "muestran la } \\
\text { realidad tal y como } \\
\text { es" es una falacia } \\
\text { porque jamás se va } \\
\text { a poder mostrar la } \\
\text { realidad porque ésta } \\
\text { realidad es muy } \\
\text { compleja muy } \\
\text { heterogénea que no } \\
\text { basta una nota de } \\
\text { 10 minutos. } \\
\text { Es verdad que } \\
\text { existe violencia en } \\
\text { el mundo: es } \\
\text { violento el hecho de } \\
\text { que una bala } \\
\text { coloquiales: } \\
\text { niño y pico de edad, } \\
\text { más la atención del } \\
\text { atravesó a un niño } \\
\text { pero también es } \\
\text { violencia la manera } \\
\text { en que se trata el } \\
\text { caso, la forma de } \\
\text { abordar el tema y } \\
\text { en los códigos } \\
\text { extralingüísticos } \\
\text { que son la música } \\
\text { de fondo que } \\
\text { generan ansiedad y } \\
\text { expectativa } \\
\text { negativa, al igual } \\
\text { que lasenes }\end{array}$ & 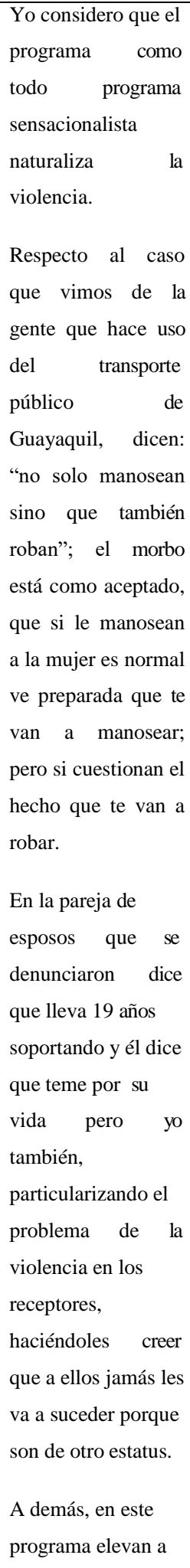 & 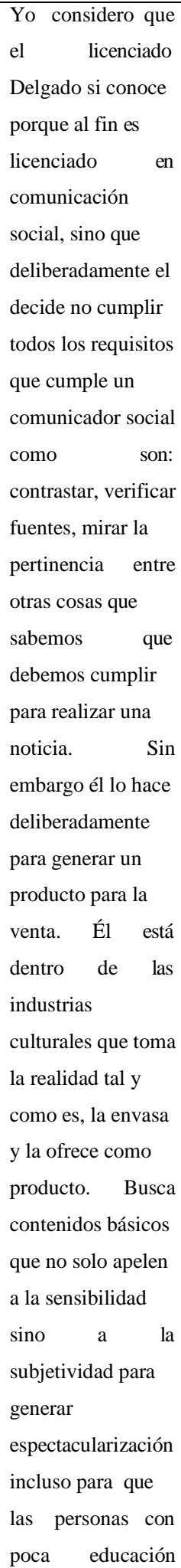 & \\
\hline
\end{tabular}


El tratamiento de la investigación periodística en el programa en carne propia

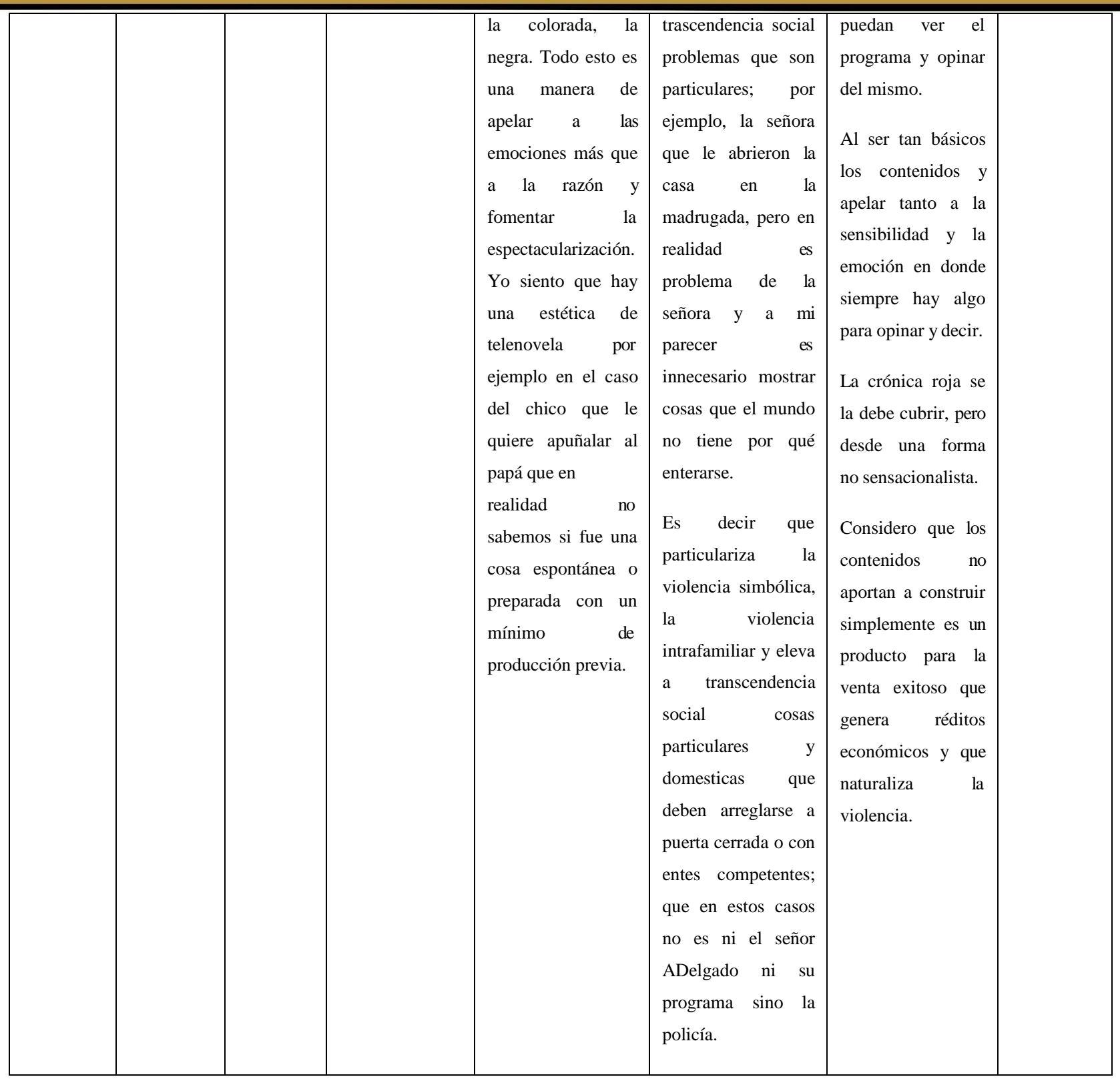

\section{Entrevistas a profundidad}

Para la entrevista a profundidad de realizó la intervención a un docente de la Carrera de Comunicación social, Lic. Franklin Falconí, Comunicador, Docente, Fundador y Redactor del quincenario “OPCIÓN”. A continuación, se muestra un ejemplo y resultados de una entrevista a profundidad: 
¿Sus nombres y apellidos completos?

Franklin Eduardo Falconí Suarez

¿En qué medio de comunicación labora y hace cuánto tiempo?

En un quincenario de la ciudad de Quito, llamado “Opción” que se inició sus labores hace quince años y del que soy fundador.

¿Qué es para Ud. el periodismo?

Hablando en términos prácticos es una actividad que toma un suceso la descontextualiza para convertirla en noticia, la interpreta y convierte en un mensaje con un sentido determinado a nivel de experiencia y a nivel de intereses del periodista y también los intereses del medio de comunicación para el que trabaja el periodista; este mensaje llega finalmente a la audiencia quien al volverlo un debate ayuda a construir una realidad circundante de la sociedad.

En sus años de periodista, mencione los principios fundamentales para un comunicador social al momento de generar información.

El periodista tiene la necesidad de cumplir con la orientación de la línea editorial del medio en que se trabaja, se determina una agenda específica noticiosa, los enfoques que se le va a dar a la noticia, las fuentes que van a ser consultadas y las que no, porque en algunos medios incluso se especifica a que fuentes no deben acudir los periodistas.

¿Cuál es el proceso periodístico o los parámetros que cumple el reportero ante un tema a desarrollar?

Desde el punto de vista editorial, es la empresa quien marca los parámetros del periodista, luego tiene que ver con la práctica de la técnica periodística, es decir el proceso de investigación y 
El tratamiento de la investigación periodística en el programa en carne propia

reportería, en la que el periodista debe buscar las versiones de todos los actores involucrados en el suceso dejando de lado las valoraciones y perjuicios personales del hecho para entender la perspectiva o punto de vista de la otra persona. Cumpliendo con estos parámetros el periodista va a recabar la información para procesarla, organizar, interpretar, destaca lo más importante y desecha lo que no considera importante para producir la noticia que repercuta en los receptores que sean objeto de reacción en la sociedad.

¿Para un periodista influye la ética más que la necesidad de tener un trabajo con el cuál sustentar una familia?

Claro, eso hace de esta profesión diferente ya que la principal arma es el arsenal ético con que está armado un periodista, le hace capaz de discernir lo positivo y negativo de los sucesos, hasta donde debe involucrarse con determinadas cosas o personas; le hace saber hasta donde son sus límites y no sobrepasarlos. El problema ético existe en los periodistas pero uno debe estar capacitado para dejar de lado las valoraciones en función de que el público esté informado objetivamente aunque no se logre un cien por ciento; pero el periodista debe buscar siempre cumplir con la objetividad en el camino que le llevará a la verdad.

¿Podría definir un concepto de periodismo de investigación?

Es aquella área especializada dedicada a tiempo completo a develar hechos que deliberadamente intentan ser ocultadas por alguien o por algo. Ese periodismo de investigación surge en EE.UU. con los conocidos casos como Watergate, pero pienso que en esencia el periodismo debe ser investigación, que todos los reporteros hagan esfuerzos para hacer un trabajo investigativo. Lamentablemente por el alto valor que significa hacer un trabajo así es que los medios y el periodismo han disminuido sus espacios para este tipo de periodismo, además que existe un 
escenario adverso en donde existe un control una censura de los cuales debe cuidarse mucho el periodista.

Para formar un equipo profesional investigativo, ¿cuál es el proceso para seleccionar el personal?

Antes que nada, que tenga una solvencia ética, que sea honesto, que la persona que va a trabajar en el medio sea franca, sincera, honesta y que no vaya a ocultar pensamientos u opiniones por quedar bien con el jefe.

Yo como jefe tenga la confianza de no correr el riesgo de ser extorsionado o de que se autocensure por temores. La segunda condición es que esté de acuerdo con la línea editorial del medio. Si una de las dos cosas falla no es posible integrar a alguien en el equipo de trabajo.

¿Cuántas personas y cuáles son los nombres de quienes conforman su equipo investigativo?

En este momento, somos cinco personas de planta; tenemos una red de colaboradores que están haciendo trabajos de ensayo, investigación y reportaje en diversas áreas como ciencia, cultura y tecnología. Este trabajo se nos ha convertido en un compromiso de tipo social político, un compromiso de decir y buscar la verdad.

¿Ha visto el desarrollo de un tema en el programa En Carne Propia?

En determinadas ocasiones.

¿Considera Ud. ¿Qué hay algo positivo dentro del trabajo periodístico que se muestra en el programa En Carne Propia?

Es un periodismo que da la posibilidad de mostrar un trabajo sin edición, de que los televidentes vean la verdad de manera cruda. En este tipo de programas quieren convencerle al televidente de 
El tratamiento de la investigación periodística en el programa en carne propia

que asisten a un hecho real, en el que el periodista es el facilitador de la persona con el hecho, desde este punto de viste sería un periodismo innovador desde la libertad que tiene el receptor de ver los hechos; pero la dificultad de esto es lo que ellos llaman la crónica roja con problemas sociales, violencia, prostitución que no muestran la realidad tal y como es; aun cuando la información no sea editada, no la contextualizan y no explican los motivos por qué se origina ese tipo de problemas. De esta manera este tipo de programas genera lo que es el morbo, buscando la manera de satisfacer ese voyerismo de la gente "mirar sin ser observado", es una condición de tipo sicológico que no construye nada en términos positivos, sino que satisface requerimientos emocionales, porque la gente condena a personajes que miran en la televisión, se identifican con lo que miran.

\section{¿Podría definir este trabajo como un periodismo de inmersión?}

No es un periodismo de inmersión, ir corriendo con cámara y micrófono detrás de los sucesos no significa que el periodista es parte de la realidad; simplemente es un ente que registra sin censura lo que sucede. El periodismo de inmersión es ser parte como actor directo de la realidad. En este programa tiene otro enfoque de show que dice "miren lo que les muestro" más no "miren lo que viví".

Considera que quienes conforman este equipo periodístico de E.C.P. cumple con los códigos deontológicos, estipulados por la Ley en nuestro país. ¿Por qué?

En realidad, no, porque existen muchos elementos de violencia, el lenguaje es discriminador y violento, se hace burla de las diferencias físicas, racial, religiosas. Evidentemente viola muchos de los preceptos del código. 
Johana M. Balseca-Mera; Lorena C. Álvarez-Garzón; Alex H. Mullo-López

Sin embargo, yo creo que no existe una sanción porque no son un riesgo para el actual régimen en términos políticos; lo que hace falta es que la gente denuncie este tipo de prácticas que no corresponde al derecho que tienen los receptores.

Es necesario dar seguimiento a los temas que se presentan en un programa como el mencionado, ¿Por qué?

Al ser un programa que muestra el drama al construir una novela con hechos de realidad; no solo este programa hay noticieros que usan esta misma lógica.

La idea de este programa no es mantenerla informada a la gente sino construir una novela para la gente. La televisión es una repetición de la realidad, en base a un esquema narrativo, el programa incita al receptor a ver las cosas que "jamás me van a pasar a mí" o crear un temor “eso me va a pasar a mí".

¿Hablamos de información o de entretenimiento?

Hablaríamos de un entretenimiento peligroso, en el sentido que se presenta como verdad, porque en el entretenimiento convencional el público está advertido del contenido que van a ver diciéndoles que no son hechos reales, advirtiéndoles incluso que no hagan en casa; pero en el programa En Carne Propia no se hace esta advertencia ni se maneja una misma clasificación de contenidos, ni tampoco se aduce que previo al programa se hace una investigación a fondo.

Usted como profesional en la comunicación; en la producción de un programa con un elevado rating, ¿descartaría la posibilidad de trabajar algún tipo de tema? ¿Por qué?

Evidentemente que sí, porque hay temas que no podrían ser parte de un programa que yo produjera, temas como racismo, homofobias, intolerancia, discriminación; yo no los haría. En la televisión ecuatoriana hay muchos programas que se pintan de humorísticos pero que en 
El tratamiento de la investigación periodística en el programa en carne propia

realidad agreden a determinados sectores de la sociedad por su condición de raza, género o cultura; se ridiculiza y genera burla o mofa. Yo no ocultaría hechos de la realidad, porque hay algo positivo en todo esto y es que de alguna u otra manera muestra a la sociedad las cosas como son, pero con otro enfoque mirando que sea un periodismo que realmente construya valores en los ciudadanos que se aleje del show de la mercantilización del morbo del espectáculo, sino que muestre una realidad de la sociedad.

\section{Resultados.}

De acuerdo a la ficha de análisis presentada del día lunes, se observa que existe una confusión en lo que respecta a la clasificación de los contenidos porque al inicio del programa se anuncia que son de tipo "B” que según el artículo 65 de la Ley Orgánica de Comunicación es: APTO PARA TODO PÚBLICO, CON VIGILANCIA DE UNA PERSONA ADULTA. SE PUEDE TRANSMITIR EN CUALQUIER HORARIO ESPECIALMENTE EN EL DE “RESPONSABILIDAD COMPARTIDA”DE 18:00 A 22:00 PERO NO EN HORARIO

FAMILIAR; sin embargo, también aparece un recuadro en una esquina que categoriza al mismo programa de tipo "entretenimiento".

En la emisión de este día, se presentan once notas, en las que sus títulos hacen referencia a testimonios, basados en experiencias personales en escenarios al sur de la ciudad de Guayaquil en los que predominan: agresiones, violencia y muerte. Es importante también tener presente que en este programa los argumentos son mayoritariamente de participación femenina.

Al componerse de cinco segmentos, en un espacio significativo el programa presenta cuatro videos internacionales que invaden redes sociales. Sin embargo, al igual que el resto de las notas, solo se describe el hecho sin brindar ninguna reflexión o llamado a que los televidentes 
Johana M. Balseca-Mera; Lorena C. Álvarez-Garzón; Alex H. Mullo-López

prevengan el tema que se está tratando y no necesariamente porque les pueda suceder lo mismo sino porque si es oportuno que el receptor haga una crítica constructiva en base al contenido que observa en el programa.

La publicidad con la que este programa trabaja se divide en cuatro espacios y se prioriza la difusión de la programación del canal en el que se emite En Carne Propia: novelas y entretenimiento son las que reiteradamente se mencionan, las marcas comerciales de productos de primera necesidad también son parte de este espacio; sin dejar de lado a un taller de televisión dictado por José Delgado a tratar el módulo: Investigación Periodística que lo publicita al iniciar el espacio.

En lo que respecta al uso de los caracteres en una entrevista (es decir la identificación de los actores de la noticia) no existe, no es posible identificar a las personas y autoridades responsables de la información que emiten en el diálogo, no se cumple con esta herramienta visual, lo que provoca una desorientación en el televidente y le resta seriedad y credibilidad. El lenguaje y vocabulario se abordan de una manera muy coloquial que a veces puede resultar vulgar al momento de enunciar un titular, determinadas palabras pueden confundirse fácilmente en un contexto, es decir se evidencia que no hay un trabajo periodístico profesional.

En nueve de cada once notas no se observa la presencia del reportero, solo es audible su voz al narrar la nota: pero en dos notas particularmente el reportero Michelino Soreano realiza pantallazos: en la primera su presencia figura con una vestimenta formal mientras que en otra nota aparece con una gorra y una bermuda, no hay coherencia en la imagen del programa y de su personal. 
El tratamiento de la investigación periodística en el programa en carne propia

Se observa también que, del total de notas presentadas, solo dos fueron tratadas anteriormente en el programa, tal es el caso de "Baleado en bar clandestino" y "gasolinera asaltada cuatro veces"; el seguimiento no concluye en solución a los temas, al contrario, mencionan que tiempo atrás se cubrió el mismo hecho con diferentes actores, pero en los mismos escenarios.

Metodológicamente, gracias al análisis y la compilación de información en base al grupo focal y las entrevistas a profundidad se puede comparar el trabajo realizado en el programa En Carne Propia y lo que autores citan en el marco del periodismo investigativo, también evidencié varias falencias en lo que concierne a la producción de éste programa, las mismas que se detallan a continuación:

En los contenidos del programa, surgen errores desde el punto de vista de la comunicación: Uso de códigos extralinguiísticos como la música de fondo que generan ansiedad y expectativa negativa, al igual que las imágenes movidas que llaman más la atención del receptor y los códigos paralingüísticos que son la locución, el uso de términos coloquiales. Apelando a las emociones más que a la razón y fomentar de esta manera la espectacularización.

El programa busca contenidos básicos que no solo apelen a la sensibilidad sino a la subjetividad de los televidentes para generar espectacularización incluso para que las personas con poca educación y menores de edad que estén frente al televisor puedan ver el programa y opinar del mismo.

De acuerdo al grupo focal las personas perciben a este programa como un espacio de entretenimiento, pero esto es un cuchillo de doble filo; porque al tiempo que los "entretiene", naturaliza la violencia en el receptor.

Pol. Con. (Edición núm. 7) Vol. 2, No 6, junio 2017, pp. 130-158, ISSN: 2550 - 682X 
Desde el punto de vista psicológico, como afirma Pablo Barba, absolutamente todas las producciones televisivas causan un determinado impacto y efecto en los televidentes. Algunos de estos efectos son direccionados a causar necesidad en los receptores y otros simplemente producen impactos que la misma producción desconoce. En el caso del programa En Carne Propia, se desatan estos efectos e impacto porque la gente que observa el programa en su mayoría lo hace sin criterio, es decir no se cuestionan la realidad o la magnitud de las notas que observan.

Para una especialista en género, las personas que aparecen en el programa aceptan y perciben el morbo hacia la mujer como algo normal, pero si cuestionan el hecho que existan: hurtos, robos, accidentes de tránsito, problemas de familia, entre otros.

\section{Conclusiones.}

Con el sustento teórico recabado en la investigación y la concordancia de autores que publican en sus obras temas comunicacionales; concluyo la importancia de saber realizar correctamente el trabajo de un comunicador social; primordialmente ser responsable al trabajar en una investigación periodística, cumplir con los códigos de ética y deontología que rigen al periodismo ecuatoriano y ser fieles practicantes de la comunicación en un medio que nos abre sus puertas para demostrar lo aprendido en la carrera universitaria.

En el mismo marco, teóricamente se sugiere a futuros investigadores, revisar la presente investigación detenidamente y de ser posible ampliar cada una de las categorías que plasmé en el marco teórico; porque éste desarrollo, les permitirá entender de mejor manera la funcionalidad de un comunicador social en el complejo mundo periodístico de la prensa la radio, la televisión entre otros. 
El tratamiento de la investigación periodística en el programa en carne propia

Mediante el análisis de contenidos se comprobó la manera en la que éste programa naturaliza la violencia en los espectadores; logrando llegar a entretener con el problema ajeno viéndose reflejados en el programa hasta cierto punto identificados con una realidad que puede o no estar lejana a su vida.

La presente investigación se convierte en un primer eslabón para llegar a conocer el trasfondo de un programa de crónica, el tema periodístico puede ser analizado a futuro por quienes estén interesados en mostrar la realidad de la sociedad sin un tinte dramático, el comunicador dejaría de ser intermediador y sería parte del problema practicando el periodismo Gonzo o el periodismo de inmersión.

\section{Recomendaciones}

Mediante la presente investigación se identificó que las personas si tienen noción de los contenidos que ven en la televisión, sin embargo, es necesario que pasen de ser espectadores pasivos a espectadores críticos que cuestionen cada programa que miran y lo socialicen en su hogar, logrando así clasificar internamente los contenidos televisivos.

El estudio del tratamiento de la investigación periodística, es necesario para impulsar al televidente a conocer y diferenciar los tipos de programas y contenidos que la televisión ofrece; y en caso de no sentir satisfacción ante estos productos denunciarlos con el respaldo que brindan los receptores de audiencias y lectores.

Los receptores deben tener la capacidad de distinguir la programación, saber si aportan de manera positiva o negativa los contenidos y de manera especial recomienda no naturalizar la violencia, discrepar entre lo real y lo que puede ser ficticio o preparado por la misma producción del programa que observen. 
Para realizar una producción televisiva, recomienda revisar los códigos deontológicos del comunicador social así como los estándares existentes para presentar una noticia, detalles pequeños como: el uso correcto del lenguaje, selección de tomas, entrevistas con caracter para conocer la identificación de quien interviene, presencia del reportero, entre otras, que permiten diferenciar un producto profesional de otro.

Con el motivo de comparar el trabajo periodístico, los estudiantes de comunicación social deben hacer énfasis en temas de investigación periodística con el fin de formarse como profesionales en los que predomine la ética en un trabajo investigativo y formativo para la sociedad.

Es importante recordar que no solo el hecho antropológico explica que se desarrollan estas escenas en la costa ecuatoriana, sino que tiene que ver con la personalidad del espectador; recomienda considerar el permitir que niños y jóvenes vean este programa porque en la edad en que comprende este grupo desarrollan una personalidad a base del aprendizaje imitación.

\section{Bibliografía.}

Arqués, R. (2003). “Periodismo de investigación”. En Relación a la verdad: (Pág. 121). QuitoEcuador: OMA Editores.

Asamblea Nacional del Ecuador (25 de Junio 2013).Artículo 10 [Título II]. Ley Orgánica de Comunicación. [Ley 22 de 2009]. DO: Tercer suplemento.

Botello, L. (2010). "Ética para el periodismo de investigación para tv". En Pasos para realizar una investigación periodística: pág. 96. Quito- Ecuador: Editorial Andes.

Burnett, J. (1996). “Comunicación social: principios y prácticas investigativas”. En Actividades operativas en la comunicación. Págs. 613-616. México: Editorial Pearson Educación.

Cardoso, M. (2010). “Investigación en la comunicación y periodismo de investigación”. En Chasqui Revista de Comunicación. Libertad de expresión. (Pág. 85). Habana: Allende editores.

Carril, M.P. (2004). "Construyendo estrategias en el consumidor". En Investigación de emociones en receptores . Pág. 323. México: editorial Litográfica Ingramex.

Gaines, W. (1996). "Periodismo investigativo para prensa y televisión”: pág. 57. Cali-Colombia: TM Editores. 
El tratamiento de la investigación periodística en el programa en carne propia

Gutiérrez M., Villaeroel M. (2008) “Géneros Televisivos”. En “Producción de televisión: géneros, lenguaje, equipo, técnicas”. Págs.: 49-57. Mexico D.F. Editorial Triallas.

Holsti, R. (2001)."Análisis de contenido cuantitativo de medios". En "Decisiones metodológicas”. Pág. 39. Barcelona:España: Editorial Girdel.

Imbert, G. (2003). "El zoo visual” En entretenimiento y diversión: pág. 39. Barcelona España:Editorial Gedisa S.A.

(2003). "El zoo visual” En La intimidad como espectáculo: de la televerdad a la telebasura: pág. 112. Barcelona-España:Editorial Gedisa S.A.

Ley Orgánica de Comunicación. (2013,25 de Junio).Registro Oficial Orgánico del Gobierno del Ecuador. $N^{\circ} 22$, Editora Nacional. www.registrooficial.gob.ec

Pinuel J.L. (2002). Epistemología, metodología y técnicas del análisis de contenido. Universidad Complutense de Madrid. Estudios de Sociolinguística3 (1),(Pág.42). Recuperado el 29 de diciembre 2015 en http://web.jet.es/pinuel.raigada/A.Contenido.pdf

Pinuel J.L. (2002). Epistemología, metodología y técnicas del análisis de contenido. En Unidades de análisis, (Pág.67). Recuperado el 29 de diciembre 2015 en http://web.jet.es/pinuel.raigada/A.Contenido.pdf

Porta,L.\&Silva,M.(2003).La investigación cualitativa: El análisis de Contenido en la investigación. Recuperado el 25 de $\quad$ diciembre 2015 en http//www.uccor.edu.ar/paginas/REDUC/porta.pdf

Rodriguez, S. (2000). “Periodismo de investigación”. En Técnicas y Estrategias. Pág. 228. Madrid-España: editorial Paidós.

San Matín, E. (1994). "Garantía de supervivencia de la prensa escrita”. En "El periodismo de investigación”: pág. 27. Madrid-España: Aula municipal de cultura.

De Trujillo, F. (2013). “José Delgado y su trabajo periodístico”. [Entrada de blog] Recuperado de http//www.fabiwaves.blogspot.com.ec/2015/02/16/ José Delgado y su trabajo periodístico/ 